\title{
La homilía de 1967 en el contexto de los escritos de san Josemaría Escrivá de Balaguer
}

\author{
The 1967 Homily in the Context of Saint Josemaría \\ Escrivá de Balaguer's Writings
}

José Luis ILLANES

Istituto Storico San Josemaría Escrivá

Roma. Italia

illanes@isje.it

Resumen: El artículo aspira a mostrar el lugar que la homilía de san Josemaría en la Universidad de Navarra, en 1967, ocupa cronológica e idealmente en el conjunto de los escritos del fundador del Opus Dei. Tras una visión panorámica de esos textos, examina los de las décadas de 1960 y 1970, época en la que san Josemaría, en plena madurez humana y espiritual, decidió completar o redactar diversos escritos destinados a exponer la espiritualidad del Opus Dei. En ese contexto la homilía de 1967 abrió la puerta a un género, el homilético, al que san Josemaría dedicó gran parte de su tiempo desde 1968 hasta su muerte. Fruto de esa labor fueron las treinta y seis homilías que integran dos de sus obras más conocidas: Es Cristo que pasa y Amigos de Dios.

Palabras clave: San Josemaría, Escritos de san Josemaría, Homilía (o Género homilético).
Abstract: This article attempts to show the chronological and conceptual locus of Saint Josemaría Escrivá de Balaguer's homily, given at the University of Navarra in 1967, within the entirety of his works. After panoramically exposing them, this article examines the works written in the 1960 and 1970 , a period in which Saint Josemaría, being in the peak of his human and spiritual maturity, decided to finish or write various works intended to explain Opus Dei's spirituality. In this context, the 1967 homily ushers in a homiletic genre that characterizes Saint Josemaría's life from 1968 until his death. Among the fruits of those years' effort are the thirty six homilies that make up two of his most renowned works: Christ is Passing by and Friends of God.

Keywords: Saint Josemaría, Writings of Saint Josemaría, Homily (or Homiletic Genre). 
7 al vez no la totalidad, pero probablemente sí la mayoría de los que asistieron a la Misa que celebró san Josemaría en la Universidad de Navarra el 8 de octubre de 1967 guardaron -algunos puede que, a pesar de los años transcurridos, todavía lo guarden- un recuerdo, más o menos detallado según los casos, de ese acontecimiento. Hasta ese momento el fundador del Opus Dei no había celebrado una Misa al aire libre ante una gran cantidad de pueblo (se calculan que estaban presentes unas 30.000 personas). Sus palabras resonaban, netas y con su característico y penetrante tono de voz, gracias a un buen sistema de audiofonía. Todo, incluido el contexto ambiental, contribuía a manifestar de forma plástica el núcleo del mensaje que el fundador del Opus Dei deseaba trasmitir: la llamada a la santidad y al apostolado en medio del mundo y, como presupuesto, la conexión entre lo cristiano y lo humano o, lo que es lo mismo, aunque con otras palabras, la valoración positiva del mundo que implica la fe cristiana. El propio san Josemaría lo señaló al comienzo de su predicación: «Reflexionad por un momento en el marco de nuestra Eucaristía, de nuestra Acción de Gracias: nos encontramos en un templo singular; podría decirse que la nave es el campus universitario; el retablo, la Biblioteca de la Universidad; allá, la maquinaria que levanta nuevos edificios; y arriba, el cielo de Navarra...». Después de unos instantes de silencio, él mismo sacaba la conclusión «¿No os confirma esta enumeración, de una forma plástica e inolvidable, que es la vida ordinaria el verdadero lugar de nuestra existencia cristiana? $\gg^{1}$.

No es mi intención proceder a un examen detenido del horizonte espiritual y teológico al que introducen esas palabras de la homilía. Aspiro, en cambio, a situarla en el contexto del conjunto de la predicación y los escritos de san Josemaría. Y esto no sólo enumerándola en la posición que cronológicamente le corresponde -dato obvio, que bastaría con señalar-, sino poniendo de manifiesto el papel que esa homilía jugó en el desarrollo de la obra escrita de san Josemaría.

A ese efecto me parece oportuno recordar un dato bien conocido. A saber, que en la actividad del fundador del Opus Dei como escritor se pueden distinguir dos periodos especialmente fecundos: la década de 1930 y los años que van desde 1960 hasta el momento de su muerte, es decir, junio de 1975. En el tiempo que medió entre uno y otro periodo su predicación -de la que se conservan

${ }^{1}$ Conversaciones, n. 113. 
numerosas notas tomadas por los oyentes y posteriormente grabaciones- fue muy abundante. También fue amplio el tiempo que dedicó a redactar guiones y a anotar ideas y consideraciones que le pudieran servir para esa predicación o para la posterior preparación de escritos ${ }^{2}$. Pero no publicó ningún libro.

Esos dos periodos, separados entre sí por un numero considerable de años, responden a situaciones muy distintas no sólo por razones históricas y ambientales, sino también biográficas,. En los años treinta san Josemaría era un sacerdote joven (había nacido en 1902 y recibido el sacramento del orden en 1925) y estaba en los inicios de la vida del Opus Dei. En las décadas de 1960 y 1970 su personalidad se había acrisolado a través de una dilatada experiencia sacerdotal y apostólica, y el Opus Dei contaba con varios millares de miembros y estaba implantado en países de las diversas partes del mundo. Y estos hechos -es lo que ahora nos interesa destacar- se reflejan en los escritos haciendo que los de cada periodo tengan características propias.

\section{LOS ESCRITOS DE LA DÉCADA DE 1930}

El 2 de octubre de 1928 san Josemaría advirtió que Dios le pedía que dedicara su existencia a promover entre cristianos de todas las condiciones y culturas la llamada a la santidad y al apostolado en medio del mundo, es decir, siendo un ciudadano más y participando por entero en las realidades que el mundo, la sociedad humana, implica ${ }^{3}$. A partir de ese momento, orientó su acción sacerdotal al servicio de ese ideal. Paralelamente se formuló a sí mismo una pregunta: ¿debo dar vida a una entidad nueva encaminada a ese fin?, ¿no puede ser preferible averiguar si existe ya una institución que promueva esa meta e incorporarme a ella? La fuerza de la experiencia espiritual del 2 de octubre no le permitió quedarse tranquilo y como a la espera de encontrar algo, sino que, desde el primer momento, comenzó a esbozar ese ideal ante quienes pensaban que podrían entenderlo y hacerlo suyo. Por lo demás, Dios le hizo ver pronto con claridad que debía dar vida a una realidad nueva.

\footnotetext{
${ }^{2}$ Para una consideración más detallada, ver ILlANES, J. L., «Obra escrita y predicación de san Josemaría Escrivá de Balaguer», Studia et documenta 3 (2009) 203-276; resumido en «Escritos de san Josemaría: descripción de conjunto», en Diccionario de san fosemaría Escrivá de Balaguer, Burgos: Monte Carmelo-Instituto Histórico Josemaría Escrivá, 2013, 390-400.

3 Sobre estos detalles biográficos y otros a los que me referiré más adelante, pueden consultarse las biografías ya publicadas, en especial VázQuez de Prada, A., El Fundador del Opus Dei. Mons. Fosemaría Escrivá de Balaguer (1902-1975), 3 vols., Madrid: Rialp, 1997-2002.
} 
Muy pronto, también, llegó a la conclusión de que, para dotar de mayor eficacia a su acción apostólica, le convendría contar con textos escritos, que pudiera entregar a quienes trataba para que los meditasen. Desde tiempo atrás -desde antes del 2 de octubre de 1928- había comenzado a anotar, en cuartillas u octavillas, que luego recopiló en cuadernos, retazos de su vida espiritual e ideas sobre lo que podría ser el proyecto apostólico al que Dios le había llamado. Pensó que esos apuntes podrían servir como apoyo escrito para su labor. De hecho los dio a leer a algunos. No tardó, sin embargo, en advertir que ese modo de proceder no era oportuno, ya que en sus cuartillas y cuadernos se pasaba sin solución de continuidad de consideraciones espirituales a detalles de su intimidad personal. De ahí que decidiera dar un paso más: seleccionar las frases o párrafos dotados de un alcance general y, con ellos, componer un libro (en un primer momento, un simple folleto escrito a máquina), apto para ser puesto a disposición de cualquiera. Nació así Consideraciones espirituales, que, en edición a velógrafo, vio la luz en 1932, y sufrió después varias adiciones y revisiones hasta dar lugar, en 1939, a Camino ${ }^{4}$.

Se ha escrito ya con abundancia sobre el estilo de Camino ${ }^{5}$. Dando por presupuestos esos estudios literarios, quiero aquí poner de relieve que el origen histórico del libro determina de modo inmediato su forma y su contenido. Camino es la obra de un sacerdote que se sabe llamado por Dios a trasmitir el mensaje del Evangelio, y a hacerlo de manera que impulse a responder a ese mensaje haciéndolo propio, aspirando de forma decidida a vivirlo con hondura en las condiciones habituales del existir del hombre en el mundo, en el ordinario acontecer y desarrollarse de la sociedad civil con las estructuras (trabajo, familia, cultura...) que la componen. Hay en el trasfondo de la predicación de san Josemaría, y concretamente en el de Camino, abundantes y valiosos presupuestos intelectuales y específicamente teológicos: la proclamación de la llamada universal a la santidad y al apostolado; la consideración del bautismo como incorporación a Cristo y, por tanto, como fuente de participación en su vida y en su misión; la reafirmación de la fuerza de la gracia, que hace posible superar el pecado y devolver su pureza original a la realidades crea-

${ }^{4}$ Sobre Consideraciones espirituales y Camino, ver la amplia y documentada introducción que se incluye en Camino. Edición critico-histórica preparada por Pedro Rodríguez, «Colección de Obras Completas de Josemaría Escrivá de Balaguer», vol. I/1, Madrid: Rialp, 2002.

5 Ver, por ejemplo, GondRAND, F., «La intención y el género literario de "Camino"», Scripta Theologica 26 (1994) 233-248; IBÁÑEZ LANGLOIS, J. M., Fosemaría Escrivá como escritor, Madrid: Rialp, 2002. 
das... En suma, una aguda percepción de la íntima relación entre creación y redención, entre naturaleza y la gracia, entre lo cristiano y lo humano. Pero todo eso, y otros puntos que pudieran mencionarse, está, como hemos indicado hace un momento, precisamente en el trasfondo, sin convertirse en ningún momento en tema de análisis.

Camino -y lo mismo cabe decir de los otros escritos de san Josemaría de la década de $1930^{6}$ - están concebidos y redactados para provocar no tanto una reflexión intelectual -aunque no la excluyen-, sino una reacción existencial, un movimiento del alma, una apertura del espíritu, una decisión de la voluntad. De ahí el tono directo; la presencia de interpelaciones que aspiran a provocar una respuesta en la que la propia persona se vea comprometida; de invitaciones a vivir de acuerdo con esa fe, esa esperanza y ese amor que forman parte esencial de la condición cristiana; de pasajes en los que se abren horizontes nuevos y se anima a lanzarse con optimismo e ilusión a la aventura, con conciencia de que será necesario afrontar dificultades y superar obstáculos, pero también de que, si se confía en Dios, se irá adelante y se harán divinos los caminos de la tierra?

\section{LOS ESCRITOS DE LAS DÉCADAS DE 1960 Y 1970}

Toda la predicación de san Josemaría, tanto en los años treinta como en los posteriores -hasta el día mismo de su fallecimiento-, estuvo informada por la fuerza espiritual que le animaba, y de la que sus escritos primeros constituyen un testimonio decisivo. De hecho la difusión del Opus Dei en los años inmediatos al 2 de octubre de 1928, y en los posteriores, no se explica sin el contacto con la persona, el talante humano y la fuerza espiritual de su fundador, bien de forma directa, bien a través de la lectura de sus escritos y, singularmente, de Camino.

Pero esa vibración y fuerza interiores, sin disminuir, se manifestaron, en las décadas de 1960 y 1970 y por lo que a su tarea como escritor se refiere, a

\footnotetext{
${ }^{6}$ Pienso no sólo en Santo Rosario (1932) y en las tres Instrucciones dirigidas a los fieles del Opus Dei (1934 y 1935), sino también en Surco y en Forja, obras análogas a Camino en las que pensó desde los años treinta y cuarenta, pero que no llegó a terminar, por lo que correspondió a su sucesor, el beato Álvaro del Portillo, la tarea de publicarlas póstumamente. Datos sobre todas ellas se pueden encontrar en los escritos mencionados en la nota 2.

${ }^{7}$ La frase final es de san Josemaría; ver, por ejemplo, Es Cristo que pasa, n. 21, Amigos de Dios, n. 314; Forja, n. 553.
} 
través de géneros literarios y de modos de expresión distintos de los de los primeros años. Los acontecimientos llevaron, en efecto, a san Josemaría, primero, desde comienzos de los años cuarenta hasta finales de los cincuenta, a reducir casi por completo su tarea de escritor y, después, desde finales de la década de 1950 hasta 1975, a adoptar un estilo no exhortativo y existencial, sino predominantemente expositivo. De esas características participa la homilía de 1967, que contribuyó a su vez a provocar una inflexión que influyó fuertemente en los textos del último periodo de la vida de san Josemaría, es decir, los de la década de 1970.

Para precisar lo que acabamos de decir, vendrá bien hacer un poco de historia. Volvamos por un momento a un dato ya apuntado. En 1936, cuando estalló la guerra civil española, formaban el Opus Dei un grupo reducido de personas: no llegaban a veinte. Durante los años de la guerra (1936-1939) algunos fallecieron o se distanciaron, pero los que perseveraron se curtieron durante aquellos años duros, como lo son los de todas las guerras. Cuando finalizó la contienda y se pudo retomar el ritmo normal de la vida y de la labor apostólica, hasta entonces contenida, el Opus Dei se expandió con fuerza, al modo como un muelle comprimido se expande al desaparecer la fuerza que le oprimía ${ }^{8}$. A mediados de los años cuarenta, el Opus Dei había extendido su labor a la casi totalidad de las ciudades españolas de importancia. Y en 1945, concluida la segunda guerra mundial, se inició la expansión por el resto de Europa y por América, tanto del norte como del sur.

Ese rápido crecimiento, unido a la necesidad de hacer frente a incomprensiones -frecuentes al surgir realidades nuevas, pero que en este caso tuvieron una especial dureza-, hicieron abordar con urgencia la oportuna configuración jurídica. Se inició así, en 1941, un itinerario jurídico, que duraría años: la novedad que en muchos aspectos implicaba el Opus Dei hacía que no hubiera en el derecho canónico un cauce adecuado, y se hiciera necesario ir dando pasos provisionales en espera de llegar a una solución definitiva ${ }^{9}$.

Ese conjunto de factores, y la atención y el trabajo que reclamaban, hicieron que, como acabamos de indicar, san Josemaría tuviera que reducir drás-

${ }^{8}$ La comparación es de san Josemaría: cfr. Camino, n. 12.

9 Sobre este proceso, ver De Fuenmayor, A., Gómez Iglesias, V. e Illanes, J. L., El itinerario jurídico del Opus Dei. Historia y defensa de un carisma, Pamplona: Eunsa, 1989. Una síntesis en GóMEZ IGLESIAS, V., «Itinerario jurídico del Opus Dei», Diccionario de san fosemaría Escrivá de Balaguer, cit., 662-672. 
ticamente su tarea como escritor durante varios años ${ }^{10}$. La reanudó, en cambio y con acentos propios, en las puertas de la década de 1960, cuando, de una parte, el desarrollo del itinerario jurídico y, de otra, la elevación al solio pontificio de Juan XXIII y la convocatoria de lo que sería el Concilio Vaticano II dieron paso a una coyuntura nueva.

El 24 de febrero 1947 y el 16 de junio 1950 el Opus Dei había recibió dos aprobaciones pontificias. Ambas fueron concedidas en el contexto de la constitución apostólica Provida Mater Ecclesia, promulgada por Pío XII el 2 de febrero de 1947, por la que se creaba la figura de los institutos seculares. La constitución apostólica daba un paso importante: implicaba, en efecto, reconocer canónicamente que el compromiso de vivir plenamente y con radicalidad el cristianismo podía darse no sólo en las órdenes y congregaciones religiosas, sino también en instituciones formadas por laicos, cristianos corrientes, y sacerdotes seculares, que aspiraran a santificarse en medio del mundo, más aún, tomando ocasión del mundo y de las actividades y tareas que lo integran (trabajo, vida familiar, economía, cultura, etc.). De ahí la denominación de «institutos seculares».

La realidad es, sin embargo, que la Provida, aun siendo un documento que quería abrir caminos, no fue al fondo de las implicaciones que trae consigo la afirmación del valor santificable y santificador de las realidades temporales, y en consecuencia dejó sueltos diversos puntos que darían lugar, poco después, a discusiones y problemas ${ }^{11}$. A fines de los años cincuenta san Josemaría vio, con absoluta claridad, que había llegado el momento de dar pasos en orden a apartarse de la figura de instituto secular y, en términos más amplios, de la vía propia de las instituciones de perfección, para buscar por otro camino la configuración jurídica del Opus Dei ${ }^{12}$. Dicho en términos más concretos: poner el acento en la misión y situarse, como ya había entrevisto de al-

${ }^{10}$ De hecho en casi veinte años sólo dio a la imprenta dos obras: un estudio canónico-teológico sobre la jurisdicción de la abadesa del Monasterio de la Huelgas (Burgos), y un texto para uso de los miembros del Opus Dei (una Instrucción, que había iniciado en 1935 y que completó en 1950, cuando la Santa Sede autorizó que se pudieran incorporar al Opus Dei también personas casadas).

${ }^{11}$ La profundización decisiva en orden a lo que apuntamos tuvo lugar sólo, por lo que a declaraciones magisteriales se refiere, en el Vaticano II, con dos de sus documentos más importantes: la constitución dogmática Lumen gentium y la constitución pastoral Gaudium et spes.

${ }^{12}$ Ver a este efecto las obras citadas en la nota 9, a las que puede añadirse ILLANES, J. L., «Apuntes para una reflexión teológica sobre el itinerario jurídico del Opus Dei», Studia et Documenta 10 (2016) 327-362. 
gún modo en los años treinta, dentro del marco de las figuras de jurisdicción personal, es decir, de lo que, años después, se designarían como prelaturas personales ${ }^{13}$.

Esta decisión hacía aconsejable, e incluso necesario, proceder a exponer y comentar, desde sus coordenadas más radicales y básicas, el espíritu del Opus Dei y dar razón de las diversas fases de la historia de su configuración jurídico-canónica. En esa dirección empujaba también el otro factor antes mencionado: la llegada al solio pontificio de Juan XXIII y la decisión, anunciada el 25 de enero de 1959, de convocar un concilio. Desde el primer momento, y luego cada vez con más intensidad a medida que progresaban las tareas conciliares preparatorias y se daban los pasos necesarios para que pudiera iniciar la asamblea, se hizo patente que el concilio, su celebración y los documentos que se aprobaran, iban a incidir fuertemente en todos los aspectos de la vida de la comunidad cristiana. Era, pues, previsible, ya desde 1959, que en las deliberaciones conciliares y, finalmente, en los documentos que se aprobaran y promulgaran iban a estar presentes algunos de los núcleos del mensaje cristiano que el espíritu y el apostolado del Opus Dei habían contribuido a proclamar y a difundir: el bautismo como fundamento de la vocación y misión del cristiano; la llamada universal a la santidad; el valor del trabajo y del conjunto de las realidades terrenas; el amor al mundo; la relación entre redención y creación, y, por tanto, entre vocación divina y vocación humana; la afirmación de la substantividad de la condición laical; la consideración del matrimonio como camino vocacional, etc.

Fue en ese contexto histórico, teológico y jurídico cómo se fraguó la evolución de san Josemaría hacia nuevos escritos; y más concretamente hacia escritos que tuvieran las propiedades propias de las exposiciones de carácter narrativo y doctrinal. El primer paso en esa dirección lo constituye la decisión de proceder a la redacción de una serie de textos destinados a los miembros del Opus Dei y encaminados a glosar, con su autoridad de fundador, las líneas básicas del espíritu, del apostolado y de la historia -especialmente la historia jurídico-canónica- de la Obra. La idea venía de muy atrás -la década de 1930y le había llevado a ir reuniendo esquemas y anotaciones. Pero la decisión de

${ }^{13}$ Sobre las prelaturas personales, ver RoDRíGUEZ, P., Iglesias particulares y prelaturas personales, Pamplona: Eunsa, 1986; DE FuenmaYor, A., Escritos sobre las prelaturas personales, Pamplona: Eunsa, 1992; VIANA, A., Introducción al estudio de las Prelaturas, Pamplona: Eunsa, 2006; BAuRA, E. (ed.), Estudios sobre la Prelatura del Opus Dei, Pamplona: Eunsa, 2008. 
completar el proyecto tomó cuerpo a fines de la década de 1950. Y con una intensidad que hizo posible que en el plazo de pocos años, entre 1960 y 1965 (o, en algún caso, 1966), completara la redacción final de un conjunto de treinta y siete documentos, a los que puso el nombre de Cartas, ya que quería expresarse con un tono familiar y directo evitando todo intento de exposición cerrada que quitara al espíritu espontaneidad y riqueza ${ }^{14}$.

Los escritos de los años treinta nos sitúan ante un sacerdote joven, que, animado por una gran fuerza interior, aspira, de palabra y por escrito, a trasmitir a quienes considera que podrían ser sus primeros seguidores la misión y los horizontes que Dios le había abierto el 2 de octubre de 1928. Los de los años sesenta, -y esta afirmación sigue siendo válida para los años setenta- colocan ante nosotros un sacerdote en edad ya madura, con una amplia experiencia pastoral y con un hondo conocimiento de la realidad viva de la Iglesia, adquirido sea en Roma (donde fijó su residencia desde 1946) sea en sus viajes por diversos países europeos y americanos, que siente la responsabilidad a dar razón del espíritu que viven a los varios millares de personas que integran el Opus Dei, así como a cuantos se acerquen a la Obra en el futuro o se interesen por su vida y por su apostolado. De ahí que el tono de los escritos que integran lo que puede ser designado como el «ciclo de las Cartas» no sea -a diferencia del de los escritos de 1930- existencial y exhortativo, sino lineal y expositivo. La dimensión apostólica y espiritual anima la totalidad de las Cartas, y, en diversos pasajes, su autor se dirige directamente al lector formulando interrogantes o interpelaciones que mueven al examen de conciencia y a decisiones operativas, pero la narración y la exposición tienen, clara y netamente, la primacía.

\section{DE LAS ENTREVISTAS A LA HOMILÍA DE 1967}

El tono expositivo que encontramos en el ciclo de las Cartas, estuvo presente, aunque con diferencias de acento, en todos los escritos posteriores de san Josemaría. Y se mantuvo también el método de trabajo entonces acuñado: partir de anotaciones personales y de transcripciones de su predicación para elaborar, a través de una serie sucesiva de revisiones, los nuevos textos que fue viendo oportuno preparar. Así ocurre con dos tipos de escritos que ocuparon

${ }^{14}$ Para una exposición más amplia sobre el origen y redacción de las Cartas, remitimos de nuevo a los escritos mencionados en la nota 2. 
un amplio espacio en los últimos años de su vida, y que, si bien pertenecen a géneros muy distintos entre sí, reflejan las características literarias recién mencionadas: las entrevistas de prensa y las homilías ${ }^{15}$.

Las entrevistas, siete en total, fueron concedidas entre 1966 y 1968, y recogidas después en un libro que llevó como título el de Conversaciones con monseñor Escrivá de Balaguer. Las homilías se extienden desde 1968 a 1974, dando lugar a dos libros: Es Cristo que pasa, editado en 1973, y Amigos de Dios, publicado póstumo en 1977. Entre la etapa final de las entrevistas y el comienzo de las homilías, se sitúa tanto cronológica como literariamente la homilía pronunciada en Pamplona en 1967: contribuyó, en efecto, poderosamente, a que san Josemaría pasara de un género a otro.

Las entrevistas de prensa se iniciaron como consecuencia de la iniciativa de un periodista francés, Jacques Guillemé-Brulon, que tuvo ocasión de encontrar al fundador del Opus Dei durante una asamblea de amigos de la Universidad de Navarra celebrada en 1964. La figura de san Josemaría le impresionó vivamente y poco después solicitó poder entrevistarlo. San Josemaría aceptó poniendo una condición: que las preguntas se formularan por escrito, de modo que él las contestaría también por escrito, recibiendo al periodista para hacerle entrega del texto ${ }^{16}$.

Al ver la entrevista ya publicada y tener noticia del eco positivo que había suscitado, san Josemaría pensó que se abría ante él una posibilidad de continuar realizando, aunque a otro nivel, el objetivo que se había propuesto con las Cartas: dar testimonio, como fundador, del espíritu y la realidad del Opus Dei, ahora ante el público en general. Esto le llevó a manifestar a sus colaboradores que estaba dispuesto a conceder nuevas entrevistas. Las peticiones llegaron pronto y entre octubre de 1966 y junio de 1968 concedió otras seis. Acogió también favorablemente la propuesta de reunirlas en un libro que se publicó en septiembre de ese mismo año, y al que se puso por título, como ya dijimos, el de Conversaciones con Monseñor Escrivá de Balaguer.

${ }^{15} \mathrm{Y}$ también a algunos escritos que, si bien no interesen a los fines de este artículo, no está de más enumerar. Se trata de textos que quiso dirigir a los fieles del Opus Dei entre 1967 y 1974, sin que formaran parte del ciclo de las Cartas, que dio por cerrado en 1966, pero que literariamente pertenecen al género epistolar y el propio san Josemaría las designó con el calificativo Cartas.

16 Apareció en el diario «Le Figaro», el 16 de mayo de 1966. Sobre la historia de las diversas entrevistas, y sobre la publicación del libro en que se recogen -y en el que se incluyó también la homilía de 1967-, ver la introducción a la edición crítico-histórica, realizada bajo la dirección de José Luis Illanes, de Conversaciones con monseñor Escrivá de Balaguer, «Colección de Obras Completas de Josemaría Escrivá de Balaguer», vol. I/3, Madrid: Rialp, 2012. 
El fundador del Opus Dei puso gran interés en la concesión de entrevistas de prensa, pero, a medida que las entrevistas se fueron sucediendo, advirtió que se trataba de una forma de comunicación que no podía prolongarse mucho: las preguntas, en efecto, tendían a repetirse y había temas -los más netamente teológicos y espirituales- que en el espacio reducido de una entrevista de prensa no podían ser tratados con toda la amplitud que sería deseable. En diciembre de 1968 tomó una decisión: no conceder de momento nuevas entrevistas, y comunicarlo así a quienes le dirigían propuestas en ese sentido ${ }^{17}$.

No consta que en ese momento hubiera pensado en otras vías para continuar la tarea de dar a la prensa nuevos escritos. Pero el hecho es que muy pronto se le presentó un camino por el que transitó durante el resto de los años que le quedaban de vida: la publicación de meditaciones u homilías. Es precisamente ahí donde jugó un papel importante la homilía pronunciada en Pamplona en octubre de 1967, a la que llega el momento de dedicar una atención especial.

En las mismas fechas en que concedía las primeras entrevistas, san Josemaría, en su calidad de Gran Canciller de la Universidad de Navarra, dio su conformidad al proyecto de celebrar, en otoño de 1967, una asamblea de la asociación de amigos de la Universidad. Entre los actos previstos para esa asamblea se encontraba, como momento central, la celebración de una Misa, que fuera al aire libre para que pudieran participar todas las personas que asistieran a la asamblea. En el seno de esa Misa se preveía que el fundador del Opus Dei pronunciara una homilía. Al aceptar esos planes, san Josemaría consideró que la homilía que debería pronunciar sería un buen momento no sólo para elogiar la labor de la Universidad y la ayuda que le prestaban sus amigos, sino también para realizar una exposición sintética de algunas de las coordinadas del espíritu del Opus Dei. A este segundo objetivo responde, de hecho, la mayor parte del texto al que llegó después de haberlo trabajado detenidamente ${ }^{18}$.

En la homilía el fundador del Opus Dei expone, en efecto, con un estilo no sólo directo, sino penetrante e incisivo, no sólo el núcleo de su mensaje, sino también algunas de las implicaciones que derivan de ese núcleo. Citemos

${ }^{17}$ Hizo sólo dos excepciones: una entrevista al diario El cruzado aragonés, de Barbastro, su ciudad natal, que apareció el 3 de mayo de 1969; y otra que solicitó un periodista del diario madrileño $\mathrm{ABC}$, amigo suyo desde décadas atrás, Julián Cortés Cabanillas (se publicó en ese diario el 24 de marzo de 1971).

18 Sobre la preparación de la homilía ver Conversaciones, 69-72. 
ante todo, a modo de ejemplo, unos párrafos muy significativos, en los que evoca su predicación a lo largo de los años: «Yo solía decir a aquellos universitarios y a aquellos obreros que venían junto a mí por los años treinta, que tenían que saber materializar la vida espiritual. Quería apartarlos así de la tentación, tan frecuente entonces y ahora, de llevar como una doble vida: la vida interior, la vida de relación con Dios, de una parte; y de otra, distinta y separada, la vida familiar, profesional y social, plena de pequeñas realidades terrenas». Y enseguida continuó, elevando la voz y con tono fuerte: $\ll_{i}$ Que no, hijos míos! no puede haber una doble vida, que no podemos ser como esquizofrénicos, si queremos ser cristianos: que hay una única vida, hecha de carne y espíritu, y ésa es la que tiene que ser -en el alma y en el cuerpo- santa y llena de Dios: a ese Dios invisible, lo encontramos en las cosas más visibles y materiales» ${ }^{19}$.

Esa solemne proclamación de la unidad de vida, está precedida por la referencia a otras verdades que tienen valor de fundamento: la bondad creacional del mundo, la llamada a la santidad en y a través de las realidades seculares, la santificación del trabajo, la trascendencia sobrenatural de la vida ordinaria vivida con conciencia de la cercanía de Dios. Y seguida por la consideración de tres de las consecuencias de ese núcleo básico: la libertad y la responsabilidad personales en el actuar profesional; el carácter secular de las obras apostólicas promovidas por fieles del Opus Dei, lo que lleva a hablar de la Universidad de Navarra, y, finalmente, la valoración del amor humano y del matrimonio ${ }^{20}$.

La continuidad entre la homilía y el conjunto de la predicación del fundador del Opus Dei es neta, pero todo buen conocedor de la doctrina y la obra de san Josemaría puede advertir a la vez que este nuevo texto está redactado de manera que queda subrayada la dimensión no sólo espiritual, sino teológica de su predicación. Desde esta perspectiva puede afirmarse que la homilía de 1967 introduce un género literario hasta entonces ausente de la obra escrita de san Josemaría: la publicación de homilías con hondo contenido teológico. $\mathrm{Y}$, en consecuencia, que abre las puertas al modo de trabajar que va a llenar sus últimos años: la revisión, con vistas a su publicación, de homilías o meditaciones previamente predicadas.

19 Conversaciones, n. 114.

20 En este sentido la homilía puede considerarse divida, materialmente aunque no formalmente, en dos partes; la primera ocupa los números 113 a 115; la segunda, los números 116-123. 


\section{De la homilía de 1967 a Es CRISTO QUE PASA y a AMIGOS DE Dios}

En 1967 el camino hacia la publicación de homilías estaba, en suma, no sólo intuido, sino abierto, pero el fundador del Opus Dei no empezó a recorrerlo de forma inmediata. De hecho, pasado el mes de octubre de 1967, san Josemaría atendió nuevas peticiones de entrevistas (concretamente, dos), sin hacer ninguna referencia a la publicación de homilías, y, cuando trabajó en la preparación de Conversaciones, decidió incluir en esa obra también la homilía de Pamplona. Para dar un paso hacia la revisión y publicación de meditaciones, hizo falta un impulso posterior, que vino muy pronto.

Una revista cultural francesa, «La Table Ronde», que estaba preparando un número monográfico sobre Jesucristo, acudió en mayo de 1968 a san Josemaría pidiendo su colaboración. Después de hacer notar que les honraría poder contar con su firma, añadían que, de ser posible, más que una entrevista, agradecerían recibir un artículo similar a -éstas fueron sus palabras- «la homilía de Pamplona», ya que -comentaban- un texto de ese estilo encajaría mejor con el tenor general de la revista ${ }^{21}$. San Josemaría aceptó la petición, pero decidió enviarles no un artículo sino una homilía sobre la resurrección de Cristo y su presencia en la Iglesia y en el cristiano; la revista la publicó en su número de noviembre de ese año, con el título Le Christ présent chez les chrétiens ${ }^{22}$.

En el momento mismo en que decidió enviar a la revista francesa una homilía, san Josemaría comenzó a pensar en la posibilidad de publicar otras: así lo manifiesta la correspondencia mantenida por esas fechas ${ }^{23}$, y lo confirman los hechos posteriores. No se cuenta con ningún documento en el que san Josemaría explique el porqué de la predilección que muestra, a partir de esa fecha, por la tarea de revisar homilías para proceder a su publicación, pero las razones parecen claras. De una parte porque, como ya dijimos, había llegado a la conclusión de que el género entrevista había dado ya de sí todo lo que podía. De otra parte -y ésta es, a nuestro juicio, la razón determinante- porque la publicación de escritos espirituales (meditaciones u homilías), preparados a

${ }^{21}$ Más datos, en la introducción a la edición crítico-histórica, preparada por Antonio Aranda, de Es Cristo que pasa, «Colección de Obras Completas de Josemaría Escrivá de Balaguer», vol. I/4, Madrid: Rialp, 2013, 42-60.

${ }^{22}$ «Le Christ présent chez les chrétiens», La Table Ronde 250 (1968) 157-172.

23 Se trata de la correspondencia dirigida a diversos países a los que se envió el original castellano -la versión francesa fue realizada en la revista que la había solicitado-, indicando que podían hacer gestiones para publicarla sea en el original castellano sea traducida a otros idiomas. Ver datos más concretos en la edición crítico-histórica de Es Cristo que pasa, 42-44. 
partir de textos de su predicación oral se le presentó como una vía para mantener contacto con los medios de comunicación social, y con sus lectores, especialmente acorde con su condición sacerdotal. Y, más concretamente, con su afán por anunciar a Cristo y por impulsar a todos los cristianos -también los que viven en medio del mundo, entregados a las más diversas ocupaciones terrenas- a amarle con todo el corazón, a orientar sus vidas de acuerdo con su mensaje y a identificarse con Él.

A partir de 1973 dedicó una amplia parte de su tiempo a esta tarea. Tomó como punto de partida meditaciones de las que se conservaban transcripciones amplias o grabaciones, y procedió a perfeccionarlas y enriquecerlas: completar o añadir citas de la Escritura, ampliar algunas ideas, incluir citas de los Padres de la Iglesia o de figuras representativas de la tradición cristiana, etc. Cuando no había transcripciones, partió selecciones de textos de su predicación relacionados con la fiesta o el tema que deseaba tratar, ordenándolos y sometiéndolos al mismo proceso de enriquecimiento que las transcripciones.

La homilía Cristo presente en los cristianos versaba sobre la fiesta de la resurrección. Las que inmediatamente le siguieron versaron también sobre fiestas litúrgicas o de gran arraigo en la tradición cristiana, hasta componer un libro, Es Cristo que pasa, que comprende dieciocho homilías que recorren la totalidad del año desde el Adviento y la Navidad hasta Pentecostés, la Asunción de la Virgen y Cristo Rey. Se terminó de editar en marzo de 1973.

La publicación de esa obra no representó a los ojos de san Josemaría el final de un proyecto, sino más bien el fin de una etapa que impulsaba a iniciar otras. En efecto, ese mismo año 1973 comenzó a revisar y completar nuevas homilías, con el deseo de dar vida a un libro que fuera de algún modo complementario del anterior, pasando de la meditación sobre las realidades litúrgico-dogmáticas a la consideración de las virtudes y de la vida espiritual del cristiano. Antes de su fallecimiento (junio de 1975) llegó a terminar y a publicar a modo de folleto siete homilías. Dejó, además, muy avanzadas, aunque necesitadas de una última revisión, otras once; su sucesor, el beato Álvaro del Portillo, asumió la tarea de realizar, siguiendo la orientación fijada por san Josemaría, esa revisión. En 1977 vió la luz un nuevo libro en el que se publicaban esas dieciocho homilías: Amigos de Dios ${ }^{24}$. El eco obtenido por esos dos

${ }^{24}$ No se cuenta todavía con una edición crítico-histórica de Amigos de Dios, aunque se encuentra en preparación. Mientras tanto puede consultarse ARANDA, A., «Amigos de Dios», Diccionario de san Fosemaria Escrivá de Balaguer, cit., 95-99. 
libros, y los frutos espirituales que han producido, muestran el acierto de san Josemaría al recorrer el camino de la revisión y publicación de homilías ${ }^{25}$.

$\mathrm{Al}$ comenzar este artículo manifesté que aspiraba a señalar el lugar que la homilía pronunciada en Pamplona en octubre de 1967 ocupa en el conjunto de la obra de san Josemaría. Y, más concretamente, en el conjunto de la obra publicada durante su vida o dejada por él ya lista para su publicación, aunque ésta (como ocurre con las Cartas) quedara para después. Espero haberlo conseguido. Para hacerlo he recorrido, aunque en líneas muy generales y dejando amplios huecos, el conjunto de la obra de san Josemaría. Y puesto de relieve, como consecuencia, la existencia en su obra escrita de una variedad de géneros literarios o expresivos: desde los textos de tono existencial y parenético de los años treinta, a los expositivos y reflexivos de los años sesenta y setenta. Diferencia que obedece, en parte, al paso de los años, con todo lo que ese paso trae consigo, pero, sobre todo -y con esta consideración podemos terminar-, a la vinculación entre su tarea como escritor y su labor como fundador, es decir, a su obediencia a la misión espiritual y apostólica que Dios le había hecho ver el 2 de octubre de 1928.

${ }^{25}$ Completemos la exposición señalando que en los mismos años en que preparaba Es Cristo que pasa y Amigos de Dios, concretamente entre 1972 y 1974, san Josemaría dio a la imprenta otras tres homilías de temática eclesiológica -y en algunos aspectos paralelas a las Cartas mencionadas en la nota 15-, que, en vida de su autor, se publicaron sólo en forma de folletos. Después de su fallecimiento, en 1986, la editorial Palabra las publicó, junto con dos escritos del beato Álvaro del Portillo, en un libro al que tituló Amor a la Iglesia (Madrid: Palabra, 1986). Está prevista la publicación de esas tres homilías, en edición crítico-histórica, en un volumen de Escritos varios de la «Colección de Obras Completas de Josemaría Escrivá de Balaguer», ahora en preparación. 


\section{Bibliografía}

ARANDA, A., «Amigos de Dios», Diccionario de san Fosemaria Escrivá de Balaguer, Burgos: Monte Carmelo, 2013, 95-99.

Baura, E. (ed.), Estudios sobre la Prelatura del Opus Dei, Pamplona: Eunsa, 2008.

De Fuenmayor, A., Gómez Iglesias, V. y Illanes, J. L., El itinerario jurídico del Opus Dei. Historia y defensa de un carisma, Pamplona: Eunsa, 1989.

De Fuenmayor, A., Escritos sobre las prelaturas personales, Pamplona: Eunsa, 1992.

Del Portillo, Á., Amor a la Iglesia, Madrid: Palabra, 1986.

Gómez Iglesias, V., «Itinerario jurídico del Opus Dei», Diccionario de san Fosemaría Escrivá de Balaguer, Burgos: Monte Carmelo, 2013, 662-672.

Gondrand, F., «La intención y el género literario de "Camino"», Scripta Theologica 26 (1994) 233-248.

IbáÑEZ Langlois, J. M., Fosemaría Escrivá como escritor, Madrid: Rialp, 2002.

Illanes, J. L., «Obra escrita y predicación de san Josemaría Escrivá de Balaguer», Studia et documenta 3 (2009) 203-276.

ILLANES, J. L., «Apuntes para una reflexión teológica sobre el itinerario jurídico del Opus Dei», Studia et Documenta 10 (2016) 327-362.

RodríGuEZ, P., Iglesias particulares y prelaturas personales, Pamplona: Eunsa, 1986.

VÁzqueZ de Prada, A., El Fundador del Opus Dei. Mons. Fosemaría Escrivá de Balaguer (1902-1975), 3 vols., Madrid: Rialp, 1997-2002.

VIANA, A., Introducción al estudio de las Prelaturas, Pamplona: Eunsa, 2006. 